\title{
Assessing health-seeking behaviour and malaria prevention practices among communities in four districts of the Volta Region of Ghana
}

Verner N. Orish ${ }^{1}$, Raymond Saa-Eru Maalman ${ }^{1 *} \mathbb{0}$, Otchere Y. Donkor ${ }^{1}$, Barbara Yordanis Henandez Ceruantes ${ }^{1}$, Eric Osei ${ }^{2,3}$, Hubert Amu², Prince Kubi Appiah 2,3, Kennedy Diema Konlan ${ }^{3,4}$, Hadiru Mumuni ${ }^{4}$, Eunji Kim5, Siwoo Kim ${ }^{6}$, Hajun Jung ${ }^{6}$, Jones Ofori-Amoah', Philip Kofie², Martin Adjuik², Robert Kaba Alhassan', Ernestina Safoa Donkor ${ }^{4}$, Francis Bruno Zottor ${ }^{2}$, Margaret Kweku², Paul Amuna², So Yoo Kim ${ }^{6}$ and John Owusu Gyapong ${ }^{8}$ and the UHAS-Yonsei Project Team

\begin{abstract}
Background: Malaria is a preventable disease that causes huge morbidity and mortality in malaria-endemic areas, especially among children and pregnant women. The malaria control programme focuses on the prevention of mosquito bites using insecticide-treated nets (ITNs) and mosquito aerosol sprays and coils, as well as prevention of severe disease among those infected through prompt and adequate treatment. The success of the malaria control programme in Ghana is dependent on the malaria prevention practices of people in the community. Therefore, this study evaluated the malaria prevention practices of participants in four districts of the Volta Region of Ghana.

Methods: This was a cross-sectional study conducted in Ketu South, Nkwanta South, Hohoe Municipality and Ho West districts of the Volta Region of Ghana. Questionnaire were administered to adults who consented to each household visited. Questions were asked on the socio-demographics and malaria prevention practices of the households. Data analysis was done using SPSS version 23 with frequency distribution done for all the variables. Pearson chi-square was used to determine the significant association between socio-demographics and malaria prevention practices, and Multivariate nominal logistic regression analysis was used to model the relationship between dichotomous dependent variables (ITN ownership and usage) and independent variables.
\end{abstract}

Results: Out of the 2493 participants; 2234 (89.6\%) owned ITN and 1528 (68.4\%) used ITN a night before this study, 768 (30.8\%) used mosquito aerosol spray and 368 (15\%) used mosquito coil. More females significantly owned ITN than males $(1293,92.4 \%, \mathrm{p} \leq 0.001)$. Participants from Ketu South had 1.5 times higher odds of owning an ITN compared to Ho West whose odds are not different from Nkwanta South or Hohoe (AOR, 1.56 [95\% 1.09-2.22]; $p=0.01$ ). In terms of ITN usage, participants in Nkwanta South were less likely to use ITN compared to the other districts; AOR, 0.434 [95\% Cl $0.31-0.62, \mathrm{p}<0.001$ ]. Also, of the 668 participants that had a fever within the past 3 days, $268(40.1 \%)$ visited a patent medicine store and 156 (23.4\%) visited health facilities.

*Correspondence: rmaalman@uhas.edu.gh

1 School of Medicine, University of Health and Allied Sciences, Ho, Ghana

Full list of author information is available at the end of the article original author(s) and the source, provide a link to the Creative Commons licence, and indicate if changes were made. The images or other third party material in this article are included in the article's Creative Commons licence, unless indicated otherwise in a credit line to the material. If material is not included in the article's Creative Commons licence and your intended use is not permitted by statutory regulation or exceeds the permitted use, you will need to obtain permission directly from the copyright holder. To view a copy of this licence, visit http://creativecommons.org/licenses/by/4.0/. The Creative Commons Public Domain Dedication waiver (http://creativeco mmons.org/publicdomain/zero/1.0/) applies to the data made available in this article, unless otherwise stated in a credit line to the data. 
Conclusion: There is high ownership of ITNs, but relatively low utilization among the community members. Education on malaria prevention practices should be intensified and continuous among the population of the Volta Region to ensure the success of malaria control in the region.

Keywords: Malaria, Insecticide treated nets (ITNs), Malaria prevention, Control, Sub-Saharan Africa, Ghana

\section{Background}

Malaria is a serious public health issue causing preventable morbidity and mortality in malaria-endemic areas worldwide, especially in sub-Saharan African $[1,2]$. In sub-Saharan Africa, where Plasmodium falciparum is responsible for the majority of malaria cases, there is an unevenly high burden of malaria, constituting about 93\% and $94 \%$ of the global 409 million malaria cases and 229 million deaths, respectively [2]. These result in an estimated loss of over 35 million Disability Adjusted life years [1-3]. Despite the appreciable reduction of malaria cases and deaths in the region due to control and prevention programmes, malaria still poses a threat to millions of lives in sub-Saharan Africa [1,2].

Malaria control and prevention has evolved over the years, with the World Health Organization (WHO) initiation of the Rollback malaria programme in 1998 focused on reducing malaria cases by $50 \%$ by the year 2010 . The WHO Global Technical Strategy for Malaria 2016-2030 focuses on the reduction of malaria burden by $90 \%$ by the year $2030[4,5]$. In summary, malaria control and prevention is focused on mortality and infection prevention. Mortality prevention employs the strategy of adequate case management involving prompt diagnosis followed by effective treatment; while infection prevention uses vector control strategies like eradication of mosquitoes through indoor and outdoor sprayings, and preventing human bite using insecticide-treated bed nets (ITNs) [57]. One of the major challenges of these control strategies is inadequate prevention practices among the targeted population or communities [6].

Malaria prevention practices among individuals in a community is one of the factors that contribute to the success of malaria control programmes in target populations [7]. How well individuals in a community embrace and assimilate the practices of malaria control and prevention activities will determine the success of the programme in achieving the desired outcomes of reduced malaria morbidity and mortality in the community [6, 7]. Health-seeking behaviour for malaria treatment is fundamental in the success of mortality prevention of malaria $[8,9]$. Some decisions taken after the onset of putative malaria symptoms include staying home and doing nothing, treatment with herbal medication, selfmedication with over-the-counter drugs, and visits to the health facilities $[8,9]$. Fever is the most common symptom for malaria, but unfortunately shares commonality with other febrile illnesses that are also prevalent in malaria endemic areas [10]. It is, therefore, pertinent that persons with fever should seek appropriate care to rule out malaria or other causes of febrile illness [10]. Any decision that does not ultimately result in prompt diagnosis and treatment might result in fatal consequences, especially among children [11]. The ITN is a very beneficial malaria prevention tool [12] that has still not reached $100 \%$ uptake in many malaria-endemic areas $[12,13]$. Though the mass distribution of ITN has been employed, its uptake has been marred by several logistics challenges; as well as poor usage by households who own ITNs, caused by several factors including inadequate number of ITNs for all the members of the household [13]. Insecticidal indoor spraying, a vector control strategy that is commonly practised in malaria-endemic areas, is also effective in preventing bites from nuisance mosquitoes [14]. It involves insecticides in aerosol spray cans and mosquito coils which target adult flying or resting mosquitoes [15-17].

In Ghana, malaria is still endemic, contributing to $4 \%$ and $7 \%$ of global malaria cases and malaria burden in West Africa, respectively [18, 19]. Malaria control and prevention in Ghana has undoubtedly yielded some desired outcomes with close to $50 \%$ reduction in malaria cases from 2005 to 2015, and a decline in malaria-related deaths from $19 \%$ to about $4.2 \%$ in 2016 $[18,19]$. With the early participation in the Rollback malaria programme, Ghana has made enviable strides in ITN campaign and coverage in the country, with $73 \%$ household ownership in 2016 from 68\% 2 years earlier [20]. With the availability of effective treatment and an improvement in easy access to healthcare through the national health insurance scheme, in addition to availability of primary healthcare centres in the communities, there was improved access to effective malaria treatment in Ghana [19, 20]. Despite these laudable interventions, there are still challenges experienced in malaria control in Ghana [18]. ITNs ownership coverage is uneven within the country with $42 \%$ in greater Accra and 52\% in the Volta Region [20]. More so, ownership does not translate to usage, as only $42 \%$ of those who own ITN sleep under it [20]. Besides, improvement in the healthcare system has not improved the malaria treatment-seeking behaviour of the people, as reports 
show that some people still use self-medication, herbal treatment and other informal treatment in the management of malaria [21,22]. With the changing and uneven trends of malaria prevention activities in the country, it is very apt for a constant evaluation of the progress of malaria control and prevention programmes at the district and regional levels in Ghana. Thus, this study was conducted to assess health-seeking behaviour and malaria prevention practices in four districts in the Volta Region of Ghana.

\section{Methods}

\section{Study site and population}

The survey was conducted in the Volta Region of Ghana. The region is one of the 16 regions in the country (previously 10) (Ghana Statistical Service [GSS], 2013). The Volta Region is located between latitudes $50^{\circ} 45^{\prime \prime} \mathrm{N}$ and $80^{\circ} 45^{\prime \prime} \mathrm{N}$ along the southern half of the eastern border of Ghana, which it shares with the Republic of Togo. The region shares boundaries to the west with Greater Accra, Eastern and Brong Ahafo regions, to the north with the Northern Region, and has the Gulf of Guinea to the south. The region's total land area is 20,570 square kilometres, representing $8.7 \%$ of the total land area of Ghana (GSS, 2013); and a population of $1,865,332$, with about $72 \%$ living in rural areas. The Volta Region has a total of 326 health institutions, out of which 242 are administered by the GHS, 18 are missionary-owned, one is quasigovernment, and 65 are privately owned (GSS, 2013).

\section{District characteristics}

The study was conducted in four districts/municipalities out of the 18 districts/municipalities of the Volta Region. These four districts/municipalities include Ho West District, Ketu South, Nkwanta South (now in the newly created Oti Region) and Hohoe Municipalities. According to the 2010 Population and Health Census of Ghana, the total number of households in Hohoe is 43,329, Ketu South is 39,119 , while Ho West and Nkwanta South have
23,875 and 22,733 respectively. Ketu south municipality is one of the study sites with the highest percentage of urban population (46\%), which according to the Ghana statistical service population health census data of 2010 makes it the second most urbanized municipality in Ghana, second to Keta municipality [23]. Nkwanta south municipality has the highest percentage of people who are defined as illiterates [24], while the percentage of population employed for all the four districts in this study is almost similar $[25,26]$. The study population from these sites comprised men and women aged 18-70 years from selected households (Table 1).

\section{Study design}

This was a cross-sectional household survey involving a multi-staged sampling of household members between the ages of 18 to 70 years. The first stage involved random sampling of four districts from the three ecological zones (savanna, middle, and coastal zones) of the region. Ketu South district was selected for the coastal ecological zone, Nkwanta South district for the savanna, while Ho West and Hohoe were selected for the middle zone.

The second stage of the sampling involved the use of a simple random sampling of thirty communities from each of the study sites; and in each community, fifteen households were randomly selected for the third stage. For the selection of the 15, the random walk technique was adopted. With this technique, interviewers selected the first housing unit by moving clockwise from the centre of the community and then followed a specific path of travel to select the rest of the housing units. Finally, the fourth stage of the sampling involves the random sampling of the available adults in each household sampled.

\section{Sample size}

Based on the 2010 populations of the household for the four districts' populations, Yamane's (1998) formula for sample size determination was used to determine the minimum number of participants for this study.

Table 1 District characteristics

\begin{tabular}{lllll}
\hline Characteristics of districts & Ho west & Ketu south & Nkwanta south & Hohoe \\
\hline Population & 94,600 & 160,756 & 117,878 & 167,016 \\
Total \# House hold & 23,875 & 39,119 & 22,733 & 43,329 \\
\%population in urban areas & $10.9 \%$ & $46 \%$ & $25.6 \%$ & $52.6 \%$ \\
population of $>15$ & 60,069 & 100,044 & 64,832 & 107,085 \\
\% population of illiterate & $14.1 \%$ & $28.1 \%$ & $47.3 \%$ & $11.7 \%$ \\
\% population of employed & $62.4 \%$ & $64.5 \%$ & 68.3 & 60.5 \\
\hline
\end{tabular}

SOURCE: Districts analytical report, GSS (2014) 
With the formula $\mathrm{n}=\frac{N}{1+N(\propto)^{2}}$. Where $\mathrm{n}$ is the minimum sample size to be determined, $\mathrm{N}$ is the study population, and $\alpha$ is the margin of error which was 0.05 at a significance level of $95 \%$ and adding $10 \%$ non-response rate, the minimum participants for the four districts were 436 for Ketu South, 433 for Ho West, 437 for Hohoe, and 432 for Nkwanta South resulting in a minimum sample size total of 1738 participants.

\section{Data collection procedure}

Data were collected with a structured questionnaire electronically administered using a Computer Assisted Personal Interview (CAPI) installed in smartphones of data collectors. The data collection exercise took place from February to April 2019 from 9 am to 2 pm each weekday. Information to highlight the sociodemographic characteristics of the participants were obtained, and these included age, gender, level of education, religion and occupation.

Occupation was categorized into farming, trading, skilled and unskilled labour, civil servants, unemployed and "others". Farming includes those involved in animal rearing and land cultivation, while trading includes both petty and large-scale trading. Skilled labour includes electricians, painters, carpenters and other skilled artisans, while unskilled labour includes porters, cleaners, bus conductors. Civil servants are all those employed in the formal sector, including teachers, accountants, healthcare workers, security personnel, administrators. Unemployed includes those without any form of employment and source of income, and these include students and other adults without employments. Other category of occupation, designated as "others", includes volunteer workers, town criers, priests, pastors and imams, toll collectors.

Questions on health-seeking behaviour were also asked; they included: whether fever was experienced in the past 3 days, and what was done after the onset of symptoms. Questions on ownership, use of ITN and the use of sprays and/or coils, as well as the use of other vector control practices, were also asked.

\section{Data analysis}

Electronic data were downloaded into a single master (Microsoft excel 2016 spreadsheet) database following completion of the fieldwork and Statistical Package for the Social Sciences (SPSS) version 22, was used for analysis. Descriptive statistics comprising frequencies and proportions were used to summarize sociodemographic variables and malaria prevention practices among the participants. Chi-square was used to test for significance of associations between socio-demographic variables and malaria prevention practices such as ownership and use of ITN, and health-seeking behaviour like actions taking after the onset of fever among participants. Multivariate nominal logistic regression analysis was used to model the relationship between dichotomous dependent variables and independent variables. The dichotomous dependent variables are ITN ownership and ITN usage. The independent variables used in the multivariate logistic regression were sociodemographic variables that had significant association with ITN Usage and Ownership in Chi-square analysis. Odds ratios, 95\% confidence limits and p-values were reported. All analyses were done using $95 \%$ confident intervals and statistical significance set as $\mathrm{p} \leq 0.05$.

\section{Ethical considerations}

Ethical clearance for the survey was obtained from the UHAS Review Ethics Committee (UHAS-REC A.6 [7] 17/18). Permission was also sought from the district/ municipal health directorates and traditional authorities of the various communities before data were collected. Written informed consent was obtained from participants before including them in the study. Confidentiality was also ensured by using initials and questionnaire number codes instead of real names.

\section{Results}

\section{Socio-demographic characteristics}

The sociodemographic characteristics are summarized in Table 2. A total of 2493 participants took part in this study, with 56\% (1400) and 44\% (1093) comprising females and males, respectively. Most participants were between the ages of 18-29 (612; 25\%), while the least number of them is seen among those from 70 years and above $(151 ; 6.1 \%)$. Ketu south district had the highest number of participants $(834 ; 34 \%)$, while Nkwanta south had the least number of participants $(446 ; 18 \%)$. Christianity was the modal religion among the participants (2154; 86\%); and the majority had Junior high school (JHS) as their highest level of education (994; 40\%). Farming was the highest occupation of the participants (742; 30\%), while 283 (11\%) of them were unemployed (Table 2).

\section{Health-seeking behaviour and malaria prevention practices}

Table 3 shows health-seeking behaviour and malaria prevention practices among the participants. A total of 668 (27\%) participants affirmed that they had experienced fever within the past 3 days of the interview, of which 156 (23\%) reported they visited the hospital after the onset of the fever, 268 (40\%) patronized the pharmacy, $62(9.3 \%)$ had recourse to herbal treatment, and 140 (21\%) reported 
Table 2 Socio-demographic characteristics

\begin{tabular}{|c|c|c|}
\hline Characteristics & Frequency & $\%$ \\
\hline \multicolumn{3}{|l|}{ Gender } \\
\hline Male & 1093 & 43.8 \\
\hline Female & 1400 & 56.2 \\
\hline \multicolumn{3}{|l|}{ Age } \\
\hline $18-29$ & 612 & 24.5 \\
\hline $30-39$ & 605 & 24.3 \\
\hline $40-49$ & 509 & 20.4 \\
\hline $50-59$ & 392 & 15.7 \\
\hline $60-69$ & 224 & 9.0 \\
\hline$\geq 70$ & 151 & 6.1 \\
\hline \multicolumn{3}{|l|}{ Districts } \\
\hline Ketu South & 834 & 33.5 \\
\hline Ho West & 671 & 26.9 \\
\hline Hohoe & 542 & 21.7 \\
\hline Nkwanta South & 446 & 17.9 \\
\hline \multicolumn{3}{|l|}{ Religion } \\
\hline Christianity & 2154 & 86.4 \\
\hline Islam & 96 & 3.9 \\
\hline Traditional & 243 & 9.7 \\
\hline \multicolumn{3}{|l|}{ Education } \\
\hline None & 357 & 14.3 \\
\hline Primary & 372 & 14.9 \\
\hline JHS & 994 & 40.0 \\
\hline SHS & 532 & 21.3 \\
\hline Tertiary & 238 & 9.5 \\
\hline \multicolumn{3}{|l|}{ Occupation } \\
\hline Farming & 742 & 29.8 \\
\hline Trading & 685 & 27.5 \\
\hline Skilled labour & 437 & 17.5 \\
\hline Unskilled labour & 139 & 5.6 \\
\hline Civil servants & 155 & 6.2 \\
\hline Unemployed & 281 & 11.2 \\
\hline Others & 54 & 2.2 \\
\hline
\end{tabular}

they did not do anything. Nine (9) in 10 participants in this study stated they owned at least one ITN (2234; 89.6\%) which was predominantly obtained for free from health facilities $(1367 ; 61 \%)$. Of those who owned ITN, $1528(68 \%)$ stated they used them the night before the study. Seven hundred and sixty-eight (768; 31\%) and 368 (15\%) of the participants reported using mosquito sprays and mosquito coils, respectively. Table 3 also illustrates other actions taking by the 42 participants after their onset of fever. The majority of them took alcoholic bitters $(18 ; 42.9 \%)$ and $(17 ; 40.5 \%)$ took leftover drugs at home.

Other vector control technique employed by participants.
Table 3 Health-seeking behaviour and malaria prevention practices

\begin{tabular}{|c|c|c|}
\hline Characteristics & Frequency & $\%$ \\
\hline \multicolumn{3}{|l|}{ History of Fever within 3 days } \\
\hline Yes & 668 & 26.8 \\
\hline No & 1825 & 73.2 \\
\hline \multicolumn{3}{|l|}{ Actions taken during fever } \\
\hline Visited a health facility & 156 & 23.4 \\
\hline Visited a patent medicine store/pharmacy & 268 & 40.1 \\
\hline Visited the herbalist & 62 & 9.3 \\
\hline Did not do anything & 140 & 20.9 \\
\hline Others & 42 & 6.3 \\
\hline \multicolumn{3}{|l|}{ Ownership of ITN } \\
\hline Owned ITN & 2234 & 89.6 \\
\hline Did not own ITN & 259 & 10.4 \\
\hline \multicolumn{3}{|l|}{ Source of ITN } \\
\hline Bought personally & 51 & 2.3 \\
\hline from community programmes & 793 & 35.5 \\
\hline from a health facility & 1367 & 61.2 \\
\hline Gift from family member/friend & 23 & 1.0 \\
\hline \multicolumn{3}{|l|}{ Use of ITN previous night $(n=2234)$} \\
\hline Used & 1528 & 68.4 \\
\hline Did not use & 706 & 31.6 \\
\hline \multicolumn{3}{|l|}{ Use of mosquito spray } \\
\hline Yes & 768 & 30.8 \\
\hline No & 1725 & 69.2 \\
\hline \multicolumn{3}{|l|}{ Use of mosquito coil } \\
\hline Yes & 368 & 14.8 \\
\hline No & 2125 & 85.2 \\
\hline Use neither ITN, mosquito spay or coil & 413 & 16.6 \\
\hline \multicolumn{3}{|l|}{ Other actions taken during fever } \\
\hline Took left over drugs & 17 & 40.5 \\
\hline Took a lot of water & 6 & 14.2 \\
\hline Took alcoholic bitters & 18 & 42.9 \\
\hline Prayed & 1 & 2.4 \\
\hline
\end{tabular}

Out of 2493 participants in this study, 70 (2.8\%) participants indicated they weed the surrounding areas around their houses as a means to reduce the number mosquitoes, $46(1.9 \%)$ stated they use electric fans, $23(0.9 \%)$ said they close all doors and windows in the evening, $18(0.7 \%)$ mentioned wearing protective clothing, and $8(0.3 \%)$ stated removing and draining stagnant waters around their homes (Fig. 1).

\section{Characteristics of participants stratified by actions taken after the onset of fever}

Table 4 shows the association between the sociodemographic variables and the actions taken after the onset of fever by the 668 participants who had a fever within the 


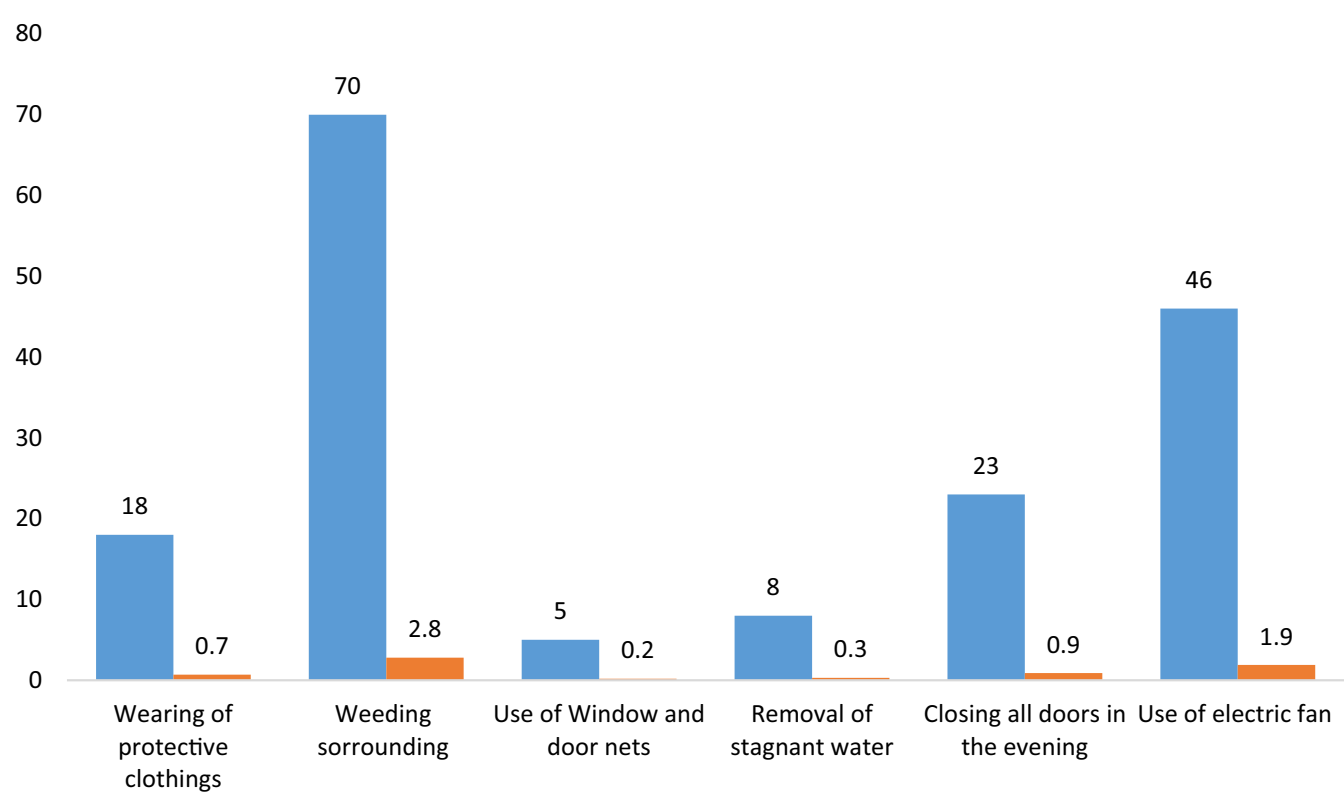

Fig. 1 Other vector control technique employed by participants

past 3 days. There was no significant difference seen in the actions taken after the onset of fever concerning sex, district, religion and highest educational level $(p>0.05)$ However, there was a significant difference noted among the different occupations $(\mathrm{p}=0.001)$, with civil servants $(7,30.4 \%)$ and traders $(57 ; 30.5 \%)$ constituting the highest proportions of participants who visited the hospital after the onset of fever and the lowest proportion seen among the unemployed $(14 ; 17.3 \%)$. Furthermore, civil servants (11; 47.8\%) were among the highest proportion of occupation that patronized patent medicine store only slightly below skilled labourers which constituted the highest proportion $(67 ; 52.3 \%)$. Unskilled labourers constituted the highest proportion of participants that resorted to herbal treatment $(6 ; 17.6 \%)$ followed by traders $(27$; 14.4\%). The unemployed 30 (37\%) constituted the highest proportion of participants that resorted to doing nothing after the onset of fever followed by unskilled labourers 9 (26.5\%).

\section{Characteristics of participants stratified by the ownership and usage of ITN}

Table 5 shows the association between sociodemographic variables and ITN ownership and usage. ITN ownership was significantly seen more with females (1293: 92.4\%, $\mathrm{p} \leq 0.001)$. Though females $(903,69.8 \%)$ slept more under ITN compared to males (625 66.4\%), this finding was not significant $(\mathrm{p}=0.13)$. There was no significant association between ITN ownership and the age groups $(p=0.16)$. However, the participants in the above 70 years age group constituted the significant lowest proportion of ITN nonusage $(37 ; 26.8 \%)$ and the highest proportion of ITN usage $(101 ; 73.2 \%)(\mathrm{p}=0.04)$. All four districts have over $85 \%$ ownership of ITN with Nkwanta South Municipality significantly having the highest proportion (424; 95.1\%, $\mathrm{p} \leq 0.001)$ and also had the significant highest proportion of participants who used ITN $(355 ; 83.7 \%, \mathrm{p} \leq 0.001)$. Religion did not have a significant association $(\mathrm{p}=0.1)$ with ownership of ITN even though participants who are traditionalist had the highest proportion (225, 92.6\%). The usage of ITN was however significant in its association with religion with participants who are traditionalist having the highest proportion $(182 ; 80.9 \%, \mathrm{p} \leq 0.001)$ of usage. Education had a significant association with ITN ownership $(\mathrm{p}=0.003)$ and usage $(\mathrm{p} \leq 0.001)$. Participants who are farmers constituted the highest proportion of those who owned $(688 ; 92.7 \%, \mathrm{p} \leq 0.001)$ and used ITN (531; 77.2\%, $\mathrm{p} \leq 0.001)$.

\section{Multivariate logistic regression analysis of the odds of owning and using an ITN}

Tables 6 and 7 show the multivariate logistic regression analysis of the odds of owning and using ITN among participants respectively. Participants from Ketu South significantly had higher odds of owning a net (Unadjusted OR, 1.60 [95\% 1.14-2.24]; $\mathrm{p}=0.01$ ]; Adjusted OR, 1.56 [95\% 1.09-2.22]; $\mathrm{p}=0.01$ ) (Table 6). Participants from Nkwanta South were significantly less likely to own an ITN (Unadjusted OR, 0.51 [95\% 0.35-0.85]; $\mathrm{p}=0.01$ ]; Adjusted OR, 0.49 [95\% 0.29-0.86]; $\mathrm{p}=0.01$ ) (Table 6). 
Table 4 Characteristics of participants stratified by actions taken after the onset of fever

\begin{tabular}{|c|c|c|c|c|c|c|c|}
\hline Characteristics & $\begin{array}{l}\text { Health facility } \\
\mathrm{N}(\%)\end{array}$ & $\begin{array}{l}\text { Patent medicine } \\
\text { store N (\%) }\end{array}$ & $\begin{array}{l}\text { Herbal treatment } \\
\mathrm{N}(\%)\end{array}$ & Nothing N (\%) & Others N (\%) & Total & $\mathbf{P}$ \\
\hline \multicolumn{8}{|l|}{ Gender } \\
\hline Male & 45 [17.7] & $113[44.5]$ & 28 [11.0] & $51[20.1]$ & $17[6.7]$ & 254 [38] & 0.06 \\
\hline Female & 111 [26.8] & 155 [37.4] & $34[8.2]$ & 89 [21.5] & $25[6.0]$ & 414 [62] & \\
\hline \multicolumn{8}{|l|}{ Age } \\
\hline $18-29$ & 39 [25.3] & 64 [41.6] & $9[5.8]$ & 37 [24.0] & $5[3.2]$ & 154 [23.1] & \\
\hline $30-39$ & 35 [19.6] & 80 [44.7] & $16[8.9]$ & 35 [19.6] & $13[7.3]$ & 179 [26.8] & \\
\hline $40-49$ & 28 [19.2] & 65 [44.5] & 17 [11.7] & 24 [16.4] & $12[8.2]$ & $146[21.9]$ & \\
\hline $50-59$ & $24[24]$ & $30[30$ & $12[12$ & $27[27]$ & $7[7]$ & 100 [14.9] & 0.13 \\
\hline $60-69$ & 18 [35.3] & 15 [29.4] & $6[11.8]$ & $9[17.6]$ & $3[5.9]$ & $51[7.6]$ & \\
\hline$\geq 70$ & 12 [31.6] & 14 [36.8] & $2[5.3]$ & $8[21.1]$ & $2[5.3]$ & $38[5.7]$ & \\
\hline \multicolumn{8}{|l|}{ Districts } \\
\hline Ketu South & 56 [23.1] & 96 [39.7] & 26 [10.7] & 50 [20.7] & $14[5.8]$ & $242[36.2]$ & \\
\hline Ho West & 35 [24.6] & 48 [33.8] & 15 [10.7] & 34 [23.9] & $10[7.0]$ & $142[21.3]$ & 0.3 \\
\hline Hohoe & 31 [21.9] & 66 [46.8] & $7[4.9]$ & 32 [22.8] & $5[3.6]$ & $141[21.1]$ & \\
\hline Nkwanta South & 34 [23.8] & 58 [40.6] & $14[9.8]$ & 24 [16.8] & $13[9.1]$ & $143[21.4]$ & \\
\hline \multicolumn{8}{|l|}{ Religion } \\
\hline Christianity & $137[24.8]$ & $222[40.2]$ & $44[7.9]$ & 120 [21.7] & $29[5.3]$ & 552 [82.6] & \\
\hline Islam & 5 [19.2] & $7[26.9]$ & $4[15.4]$ & $6[23.1]$ & $4[15.4]$ & $26[3.9]$ & 0.1 \\
\hline Traditional & 14 [15.6] & 39 [43.3] & 14 [15.6] & 14 [15.6] & $9[10]$ & 90 [13.5] & \\
\hline \multicolumn{8}{|l|}{ Education } \\
\hline None & $25[22.5]$ & 51 [45.9] & $11[9.9]$ & $16[14.4]$ & 8 [7.3] & 111 [16.6] & \\
\hline Primary & 25 [20.5] & 48 [39.3] & 14 [11.5] & 25 [20.5] & $10[8.2]$ & 122 [18.3] & 0.4 \\
\hline JHS & 61 [21.9] & $107[38.4]$ & $24[8.6]$ & 71 [25.4] & $16[5.7]$ & 279 [41.8] & \\
\hline SHS & $34[28.3$ & 46 [38.3] & $11[9.2]$ & 23 [19.2] & $6[5.0]$ & 120 [17.9] & \\
\hline Tertiary & 11 [30.6] & $16[44.4]$ & $2[5.6]$ & $5[13.9]$ & $2[5.6]$ & $36[5.4]$ & \\
\hline \multicolumn{8}{|l|}{ Occupation } \\
\hline Farming & 46 [22.9] & 81 [40.3] & $18[8.9]$ & $39[19.4]$ & $17[8.5]$ & $201[30.1]$ & \\
\hline Trading & $57[30.5]$ & 63 [33.7] & $27[14.4]$ & 30 [16.0] & $10[5.3]$ & 187 [27.9] & \\
\hline Skilled labour & 23 [17.9] & 67 [52.3] & $7[5.5]$ & 27 [21.1] & $4[3.1]$ & 128 [19.2] & 0.001 \\
\hline Unskilled labour & $6[17.6]$ & 10 [29.4] & $6[17.6]$ & $9[26.5]$ & $3[8.8]$ & $34[5.1]$ & \\
\hline Civil servants & $7[30.4]$ & 11 [47.8] & $1[4.3]$ & $2[8.7]$ & $2[8.7]$ & $23[3.4]$ & \\
\hline Unemployed & 14 [17.3] & 31 [38.3] & $2[2.5]$ & 30 [37.0] & $4[4.9]$ & 81 [12.1] & \\
\hline Others & $3[21.4]$ & $5[35.7]$ & $1[7.1]$ & $3[21.4]$ & $2[14.4]$ & $14[2.1]$ & \\
\hline
\end{tabular}

Also, participants from Nkwanta South were less likely to use ITN (Unadjusted OR, 0.35 [95\% $0.25-0.48$; $\mathrm{p} \leq 0.001$ ]; Adjusted OR, 0.40 [95\% 0.29-0.57]; $\mathrm{p} \leq 0.001$ ) (Table 7). Participants with no education (Adjusted OR, 0.32 [95\% 0.20-0.50]; $\mathrm{p} \leq 0.001$ ), primary (Adjusted OR, 0.42 [95\% 0.28-0.64]; $\mathrm{p} \leq 0.001$ ) and JHS (Adjusted OR, 0.61 [95\% 0.43-0.87]; $\mathrm{p} \leq 0.001$ ) had significantly lower odds of using ITN, respectively (Table 7).

\section{Discussion}

Fever was a fairly common reported complaint among participants (668) in this study; and it is usually a common malaria symptom that triggers the decision to seek care compared to other symptoms [10]. Fever from malaria is not easily differentiated from other causes of febrile illnesses that are replete in malaria endemic areas, and that was why the WHO recommend prompt malaria testing in patients presenting with fever [27]. Prompt malaria testing is an important component of effective case management control strategy aimed at preventing malaria mortality $[8,10,27]$. The success of this control strategy vis-à-vis prompt malaria detection and treatment among persons with fever is dependent of healthseeking behaviour of those involved [8-10].

More than half of the 668 participants who admitted to having had fever within the past 3 days, reported 
Table 5 Characteristics of participants stratified by the ownership and usage of ITN

\begin{tabular}{|c|c|c|c|c|c|c|}
\hline \multirow[t]{2}{*}{ Characteristics } & \multicolumn{2}{|c|}{ Ownership of ITN } & \multirow[t]{2}{*}{ P-value } & \multicolumn{2}{|c|}{ Usage of ITN } & \multirow[t]{2}{*}{ P-value } \\
\hline & Yes & No & & Yes & No & \\
\hline \multicolumn{7}{|l|}{ Gender } \\
\hline Male & $941[86.1]$ & 152 [13.9] & \multirow[t]{2}{*}{$\leq 0.001$} & $625[66.4]$ & $316[33.6]$ & \multirow[t]{2}{*}{0.13} \\
\hline Female & $1293[92.4]$ & $107[7.6]$ & & $903[69.8]$ & $390[30.2]$ & \\
\hline \multicolumn{7}{|l|}{ Age } \\
\hline $18-29$ & $533[87.1]$ & 79 [12.9] & \multirow[t]{6}{*}{0.16} & $358[67.2]$ & $175[32.8]$ & \multirow[t]{6}{*}{0.04} \\
\hline $30-39$ & $546[90.2]$ & $59[[9.8]$ & & $390[71.4]$ & $156[28.6]$ & \\
\hline $40-49$ & $464[91.2]$ & $45[8.8]$ & & $294[63.4]$ & $170[36.6]$ & \\
\hline $50-59$ & $355[90.6]$ & $37[9.4]$ & & $247[69.6]$ & $108[30.4]$ & \\
\hline $60-69$ & $198[88.4]$ & $26[11.6]$ & & $138[69.7]$ & 60 [30.3] & \\
\hline$\geq 70$ & $138[91.4]$ & $13[8.6]$ & & $101[73.2]$ & $37[26.8]$ & \\
\hline \multicolumn{7}{|l|}{ Districts } \\
\hline Ketu South & $720[86.3]$ & 114 [13.7] & \multirow[t]{4}{*}{$\leq 0.001$} & $477[66.3]$ & $243[33.7]$ & \multirow[t]{4}{*}{$\leq 0.001$} \\
\hline HoWest & $608[90.6]$ & $63[9.4]$ & & $398[65.5]$ & $210[34.5]$ & \\
\hline Hohoe & $482[88.9]$ & $60[11.1]$ & & $298[61.8]$ & $184[38.2]$ & \\
\hline Nkwanta South & $424[95.1]$ & $22[4.9]$ & & $355[83.7]$ & $69[16.3]$ & \\
\hline \multicolumn{7}{|l|}{ Religion } \\
\hline Christianity & 1925 [89.4] & $229[10.6]$ & \multirow[t]{3}{*}{0.1} & $1280[66.5]$ & $645[35.5]$ & \multirow[t]{3}{*}{$\leq 0.001$} \\
\hline Islam & 84 [87.5] & $12[12.5]$ & & $66[78.6]$ & $18[21.4]$ & \\
\hline Traditional & $225[92.6]$ & $18[7.4]$ & & 182 [80.9] & 43 [19.1] & \\
\hline \multicolumn{7}{|l|}{ Education } \\
\hline None & 329 [92.2] & $28[7.8]$ & \multirow[t]{5}{*}{0.003} & $265[80.5]$ & 64 [19.4] & \multirow[t]{5}{*}{$\leq 0.001$} \\
\hline Primary & $329[88.4]$ & $43[11.6]$ & & $244[74.2]$ & 85 [25.8] & \\
\hline $\mathrm{JHS}$ & 907 [91.2] & $87[8.8]$ & & $609[67.1]$ & 298 [32.9] & \\
\hline SHS & $460[86.5]$ & 72 [13.5] & & $290[63.0]$ & $170[37.0]$ & \\
\hline Tertiary & $209[87.8]$ & 29 [12.2] & & $120[57.4]$ & 89 [42.6] & \\
\hline \multicolumn{7}{|l|}{ Occupation } \\
\hline Farming & $688[92.7]$ & $54[7.3]$ & \multirow[t]{7}{*}{$\leq 0.001$} & $531[77.2]$ & $157[22.8]$ & \multirow[t]{7}{*}{$\leq 0.001$} \\
\hline Trading & $620[90.5]$ & $65[9.5]$ & & 398 [64.2] & $222[35.8]$ & \\
\hline Skilled labour & $383[87.6]$ & 54 [12.4] & & $244[63.7]$ & $139[36.3]$ & \\
\hline Unskilled labour & 115 [82.7] & 24 [17.3] & & 82 [71.3] & 33 [28.7] & \\
\hline Civil servants & $134[86.5]$ & 21 [13.5] & & 85 [63.4] & 49 [36.6] & \\
\hline Unemployed & $244[86.8]$ & 37 [13.2] & & 154 [63.1] & 90 [36.9] & \\
\hline Others & 50 [92.6] & $4[7.4$ & & $34[68]$ & $16[32.0]$ & \\
\hline
\end{tabular}

to have either sought help from a patent medicine store $(40 \%)$ or visited a health facility (23\%). The high patronage of patent medicine stores or vendors is not surprising as they are replete in many African rural settings where they provide care for patients, especially prompt malaria treatment [28-30]. Though they are not usually staffed and overseen by trained pharmacists, and not stocked with expensive malaria drugs, they are often stocked with basic and effective artemisinin-based combination therapy (ACT) dispensed by a trained medicine counter assistant [30]. More so, they are often equipped with simple RDTs to quickly arrive at a malaria diagnosis in patients with fever $[29,31]$. Visiting health facilities after the onset of fever was the second-best option for participants in this study; and it was significantly reported among civil servants and traders, probably because of the financial implications vis-a-vis the relatively higher out of pocket expenses compared to patent medicine stores $[28,32,33]$. Out of pocket expenses influence treatment-seeking behaviour for malaria, as only those with adequate finances can have the satisfaction of spending more to get the best care when sick with malaria [34]. Like most Low-and-Middle-Income-Countries (LMIC), Ghana's National Health Insurance Scheme (NHIS) is plagued with poor coverage of about $40 \%$ of the population and several other challenges, making the attainment 
Table 6 Multivariate logistic regression analysis of the odds of owning ITN

\begin{tabular}{|c|c|c|c|c|}
\hline Characteristics & Unadjusted OR (95\% Cl) & & Adjusted OR (95\% CI) & \\
\hline \multicolumn{5}{|l|}{ Gender } \\
\hline Female & $0.48(0.36-0.610$ & 0.10 & $0.55(0.39-0.69)$ & 0.12 \\
\hline Male & & 1 & 1 & \\
\hline \multicolumn{5}{|l|}{ Districts } \\
\hline Ketu South & $1.60(1.14-2.24)$ & 0.01 & $1.56(1.09-2.22)$ & 0.01 \\
\hline Nkwanta South & $0.51(0.30-0.85)$ & 0.01 & $0.49(0.29-0.86)$ & 0.01 \\
\hline Hohoe & $1.29(0.88-1.89)$ & 0.19 & $1.23(0.83-1.81)$ & 0.31 \\
\hline Ho West & 1 & & 1 & \\
\hline \multicolumn{5}{|l|}{ Occupation } \\
\hline Farming & $0.65(0.22-1.89)$ & 0.43 & $0.66(0.22-2.04)$ & 0.47 \\
\hline Trading & $0.96(0.33-2.78)$ & 0.91 & $1.37(0.46-4.06)$ & 0.58 \\
\hline Skilled labour & $1.39(0.48-4.04)$ & 0.55 & $1.34(0.45-0.395)$ & 0.6 \\
\hline Unskilled labour & $2.25(0.73-6.90)$ & 0.16 & $1.87(0.59-5.85)$ & 0.25 \\
\hline Civil servants & $1.62(0.54-5.14)$ & 0.38 & $1.46(0.46-4.99)$ & 0.52 \\
\hline Unemployed & $1.47(0.49-4.35)$ & 0.40 & $1.65(0.54-4.99)$ & 0.37 \\
\hline Others & 1 & & 1 & \\
\hline \multicolumn{5}{|l|}{ Education } \\
\hline None & $0.55(0.31-0.98)$ & 0.04 & $0.89(0.47-1.73)$ & 0.75 \\
\hline Primary & $0.85(0.50-1.44)$ & 0.55 & $1.27(0.70 .2 .30)$ & 0.43 \\
\hline JHS & $0.64(0.40-1.02)$ & 0.06 & $0.95(0.57-1.59)$ & 0.86 \\
\hline SHS & $1.15(0.72-1.85)$ & 0.56 & $1.50(0.89-2.55)$ & 0.13 \\
\hline Tertiary & 1 & & 1 & \\
\hline
\end{tabular}

ORodds ratio, $\mathrm{Cl}$ confidence interval

of Universal Health Coverage (UHC) a big challenge in the country $[35,36]$. This has made many in Ghana spend so much in out of pocket expenses in seeking health care, especially for recurrent diseases like malaria [35]; thus making the poor and those without adequate finances seek cheaper alternative treatments, such as herbal remedies [34]. Only 62 participants agreed to having taken herbal treatment for their fever, which is a rather common practice in malaria-endemic areas including Ghana $[37,38]$. Another group of participants claimed not to have done anything since the onset of their fever within the past three days, probably still observing the symptoms to either take action if symptoms persist or worsen [39]. This attitude usually leads to delay in treatment resulting in the complication of malaria especially in vulnerable groups such as children and pregnant women [30].

ITN ownership and usage (sleeping under ITN) among the participants in this study was $90 \%$ and $68 \%$, respectively. This trend of low usage of ITN despite relatively high ownership has been reported in many parts of the country [20, 40-43]. There are several reasons people give for not sleeping under ITN despite having one at home. These include the inability to mount the ITN due to lack of appropriate location in the household, complaints that sleeping under the ITN is uncomfortable due to increase warmth (due to them feeling warmer under the net), and not enough ITN to accommodate every member of the household [44, 45]. Aside these complaints, there is however inappropriate use of the ITNs, as it has been reported that some people use them for fishing, farming and other activities [46, 47]. The majority of the ITNs in this study were obtained through free means, either through health facilities $(61 \%)$ or community outreach programmes (36\%); and this might contribute to the reason for the inappropriate usage of the ITNs $[45,48]$.

Females $(92 \%)$ were found to be significantly $(\mathrm{p} \leq 0.001)$ more likely to own ITNs than males (86\%) in this study; and, although more women slept under the ITN, this finding was not statistically significant. This finding has been reported in some other studies $[49,50]$. The likelihood of females especially those of reproductive age to visit health facilities when pregnant or participate in community outreach programmes where free ITNs are distributed might explain this finding [51, 52]. Females are also prioritized to sleep under the ITNs when there are not enough ITNs in the household, and they often share ITNs with younger children $[49,50]$. Participants from Ketu south were 1.5 times more likely to own an 
Table 7 Multivariate logistic regression analysis of the odds of using ITN

\begin{tabular}{|c|c|c|c|c|}
\hline Characteristics & Unadjusted OR (95\% Cl) & & Adjusted OR (95\% Cl) & \\
\hline \multicolumn{5}{|l|}{ Districts } \\
\hline Ketu South & $0.93(0.74-1.18)$ & 0.50 & $1.04(0.81-1.33)$ & 0.73 \\
\hline Nkwanta South & $0.35(0.25-0.48)$ & $\leq 0.001$ & $0.40(0.29-0.57)$ & $\leq 0.001$ \\
\hline Hohoe & $1.18(0.92-1.52)$ & 0.20 & $1.20(0.93-1.56)$ & 0.162 \\
\hline Ho West & 1 & & 1 & \\
\hline \multicolumn{5}{|l|}{ Occupation } \\
\hline Farming & $0.65(0.22-1.89)$ & 0.008 & $0.56(0.27-1.12$ & 0.12 \\
\hline Trading & $0.96(0.33-2.78)$ & 0.59 & $1.24(0.61-2.51)$ & 0.56 \\
\hline Skilled labour & $1.39(0.48-4.04)$ & 0.67 & $1.11(0.54-2.27)$ & 0.78 \\
\hline Unskilled labour & $2.25(0.73-6.90)$ & 0.31 & $0.80(0.30-1.50)$ & 0.59 \\
\hline Civil servants & $1.62(0.54-5.14)$ & 0.90 & $0.76(0.35-1.66)$ & 0.49 \\
\hline Unemployed & $1.47(0.49-4.35)$ & 0.82 & $1.19(0.37-2.47)$ & 0.65 \\
\hline Others & 1 & & 1 & \\
\hline \multicolumn{5}{|l|}{ Education } \\
\hline None & $0.29(0.19-0.43)$ & $\leq 0.001$ & $0.32(0.20-0.50)$ & $\leq 0.001$ \\
\hline Primary & $0.40(0.28-0.54)$ & $\leq 0.001$ & $0.42(0.28-0.64)$ & $\leq 0.001$ \\
\hline JHS & $0.57(0.42-0.78)$ & 0.001 & $0.61(0.43-0.87)$ & 0.006 \\
\hline SHS & $0.73(0.22-1.02)$ & 0.68 & $0.73(0.57-1.07)$ & 0.11 \\
\hline Tertiary & 1 & & 1 & \\
\hline \multicolumn{5}{|l|}{ Religion } \\
\hline Christianity & $2.19(1.51-3.18)$ & $\leq 0.001$ & $1.77(1.17-2.67)$ & 0.01 \\
\hline Islam & $1.98(1.05-3.75)$ & 0.04 & $1.84(0.93-3.64)$ & 0.08 \\
\hline Traditional & 1 & & 1 & \\
\hline
\end{tabular}

OR odds ratio, $\mathrm{Cl}$ confidence interval

ITN, while participants from Nkwanta south were less likely to sleep under an ITN. This finding might have been influenced by the varied sociodemographic characteristics of the districts $[23,24]$. The high $\%$ population of people living in urban areas in Ketu south municipality, as well as the relative high number of people that are literate, and the opposite seen in Nkwanta south might have contributed to these findings. Education seems to influence the use of ITNs in this study; a finding similarly reported in some other studies, as participants with lower levels of education were less likely to use ITN [53-55].

Mosquito spray and coil were other methods of vector control used by participants in this study. Mosquito coils are usually cheaper alternatives compared to mosquito aerosol spray for those who do not have ITN, and it is widely used in several malaria-endemic countries including Ghana [16, 43, 55]. Mosquito aerosol spray is also widely used in malaria-endemic areas including Ghana [17, 43, 56-58]. There are no official approval or recommendation by the National Malaria Control Programme or the Ghana Health Service on the use of mosquito aerosol sprays and coils, but their use seem to be common in Ghana as some prefer them to
ITNs because of easy availability and applicability [43]. Although this study observed ITN use together with mosquito spray and coil, it is very likely that in reality they were not used together as the use of mosquito spray and coil often reduced the likelihood of the use of ITN [43]. The findings in this study show that only a few of the participants relied on mosquito spray and/or mosquito coil, a finding similar to studies done in Sunyani in Ghana and Imo State in Nigeria $[43,59]$.

This study had better ITN ownership and usage compared to some studies in other parts of Ghana [20, 41-43]. This relatively higher ITN ownership and usage might have been influenced by the rainy season when this study was done, which normally increase ITN ownership and usage [43, 60]; though this influence was not seen in ITN ownership and usage in the study done in Sunyani in Ghana [43]. However, a worrying finding is the $16.6 \%$ of the study participants who did not employ any form of vector control methods like ITN, mosquito coil and/or spray, which is much higher than $13.8 \%$ in the Sunyani study [43].

This study highlighted interesting findings concerning health seeking behaviour and malaria prevention practices in the Volta Region. However, the inherent 
complexities of health seeking behaviors and malaria preventive practices among people in communities are usually hard to conceptualize solely from responses of cross-sectional studies like this one. It might also be necessary that qualitative studies be employed to further explore the reasons behind the findings.

\section{Conclusion}

The study showed that the majority of the participants who had a fever within the past 3 days visited patent medicine stores (40\%) and health facilities (23\%). ITN ownership was $90 \%$ and usage was $68 \%$ with more females reporting to own and use ITNs than males. Participants from Ketu South were 1.5 times likely to own an ITN, while those from Nkwanta South were less likely to use ITN. Mosquito aerosol sprays and coils were also used by few participants as vector control methods. Though the percentage of ITN ownership and usage among participants in this study were relatively higher than most studies done in Ghana, it is still below the national malaria control programme target; and more worrying is that about $17 \%$ of participants practice no form of vector control, and those using mosquito coils with proven health hazards. It is, therefore, very important that education on health-seeking behaviour vis-a-vis the importance of seeking help promptly and from the right place when ill with symptoms of malaria. Education should focus on the importance of going for malaria test when there is any febrile illness, to rule out other causes of fever. Education on malaria prevention practices like the proper use of ITNs and others should be intensified and continuous among the population of the Volta Region to ensure the success of malaria control in the region. Employing the appropriate behaviour change model might be needed to design an effective education programme.

\section{Acknowledgements \\ Authors are grateful to health authorities and health staff of the Volta region for their support and permission to carry out and publish this study. We would like to acknowledge the staff of the University of Health and Allied Sciences (UHAS) who played various roles in the project. We thank village heads (chiefs and local government leadership) and students of UHAS for the role they played in the data collection.}

\section{Authors' contributions}

VNO, RSM, OYD, BYH, and EK made contributions to the conception and design of the study. EK, SW and $\mathrm{HJ}$ made a substantial contribution to the study design and management of the research activities. VNO and RSM analysed the data and VNO drafted the manuscript. All authors were involved in critical revision for important intellectual content. All authors read and approved the final manuscript.

\section{Funding}

Funding for this study was provided by the National Research Foundation (NRF) of Korea through the Public Health Education Capacity Development of University of Health \& Allied Sciences' project. The funding body apart from the funding provided had no direct control in the design of the study or collection, analysis, and interpretation of data or in writing the manuscript.

\section{Availability of data and materials}

The datasets used during the current study are available from the corresponding author on reasonable request.

\section{Declarations}

Ethics approval and consent to participate

Ethical approval was obtained from the University of Health and Allied Sciences' ethical review committee. District directors of health services of the participating districts consented before data were collected. Written informed consents were obtained from participants.

\section{Consent for publication}

Not applicable.

\section{Competing interests}

The authors declare that they have no competing interests.

\section{Author details}

${ }^{1}$ School of Medicine, University of Health and Allied Sciences, Ho, Ghana. ${ }^{2}$ School of Public Health, University of Health and Allied Sciences, Hohoe, Ghana. ${ }^{3}$ Department of Public Health Graduate School, Yonsei University, Seoul, Republic of Korea. ${ }^{4}$ School of Nursing and Midwifery, University of Health and Allied Sciences, Ho, Ghana. ${ }^{5}$ Korea Foundation for International Healthcare Ghana Office, Accra, Ghana. ${ }^{6}$ Asian Institute for Bioethics and Health Law, College of Medicine, Yonsei University, Seoul, Republic of Korea. ${ }^{7}$ Directorate of International Affairs, University of Health and Allied Sciences, Ho, Ghana. ${ }^{8}$ Office of the Vice-Chancellor, University of Health and Allied Sciences, Ho, Ghana.

Received: 8 March 2021 Accepted: 16 November 2021

Published online: 27 November 2021

\section{References}

1. WHO. Malaria burden global. Geneva, World Health Organization. Available at https://www.who.int/news-room/fact-sheets/detail/malaria. Accessed December 20th 2020

2. WHO. The World malaria report 2019 at a glance. Geneva, World Health Organization. Available at https://www.who.int/news-room/feature-stori es/detail/world-malaria-report-2019. Accessed December 20th 2020

3. Gunda R, Chimbari MJ, Mukaratirwa S. Assessment of burden of malaria in Gwanda District, Zimbabwe, using the disability adjusted life years. Int J Environ Res Public Health. 2016;13:244.

4. WHO. Evolution of malaria control programme. Geneva, World Health Organization. Available at https://www.who.int/malaria/news/2015/ governing-board-disbands-rbm-secretariat/en/.

5. Shiff C. Integrated approach to malaria control. Clin Microbiol Rev. 2002;15:278-93.

6. Tizifa TA, Kabaghe AN, McCann RS, van den Berg H, Van Vugt M Phiri, KS. Prevention efforts for malaria. Curr Trop Med Rep. 2018;41-50.

7. Musoke D, Karani G, Ssempebwa JC, Etajak S, Guwatudde D, Musoke MB. Knowledge and practices on malaria prevention in two rural communities in Wakiso District, Uganda. Afr Health Sci. 2015;15:401-12.

8. Workineh B, Mekonnen FA. Early treatment-seeking behaviour for malaria in febrile patients in northwest Ethiopia. Malar J. 2018;7:406.

9. Gerald M. Assessing factors influencing health seeking behaviour for malaria treatment in children under five years in Rwimi Town Council Kabarole District. Int J Sch Cogn Psychol. 2015;2:151.

10. Atkinson JAM, Fitzgerald L, Toaliu H, Taleo G, Tynan A, Whittaker M, Riley I, Vallely A. Community participation for malaria elimination in Tafea Province, Vanuatu: Part I. Maintaining motivation for prevention practices in the context of disappearing disease. Malar J. 2010;2010(9):1-16.

11. Mitiku I, Assefa A. Caregivers' perception of malaria and treatment-seeking behaviour for under five children in Mandura District, West Ethiopia: a cross-sectional study. Malar J. 2017;16:144. 
12. Jones G, Steketee RW, Black RE, Bhutta ZA, Morris SS, Bellagio Child Survival Study Group. How many child deaths can we prevent this year? Lancet. 2003;362:65-71.

13. Kilian A, Wijayanandana N, Ssekitoleeko J. Review of delivery strategies for insecticide treated mosquito nets: are we ready for the next phase of malaria control efforts? TropIKA.net. 2010;1:1.

14. Corrêa APS, Galardo AK, Lima LA, Câmara DC, Müller JN, Barroso JFS, et al. Efficacy of insecticides used in indoor residual spraying for malaria control: an experimental trial on various surfaces in a "test house." Malar J. 2019;8:345.

15. WHO. House-spraying with residual insecticides. Geneva, World Health Organization. Available at https://www.who.int/water_sanitation_health/ resources/vector357to384.pdf. Accessed December 20th 2020

16. Hogarh JN, Antwi-Agyei P, Obiri-Danso K. Application of mosquito repellent coils and associated self-reported health issues in Ghana. Malar J. 2016;15:61.

17. Pemba D, Kadangwe C. Mosquito control aerosols' efficacy based on pyrethroids constituents. In: Insecticides -advances in integrated pest management. Perveen FK, Ed. INTECH Open Access Publisher. 2012.

18. WHO. Ghana malaria cases. 2018. Available at https://apps.who.int iris/bitstream/handle/10665/275867/9789241565653-eng.pdf?ua=1. Accessed December 20th 2020.

19. Ghana Severe Malaria Observatory. Available at https://www.severemala ria.org/countries/ghana. Accessed December $20^{\text {th }} 2020$.

20. Workshop DHSP. Ghana Malaria Indicator Trends. Available at https:// dhsprogram.com/pubs/pdf/OD72/OD72.pdf. Accessed December 20th 2020.

21. Awuah RB, Asante PY, Sakyi L, Biney AA, Kushitor MK, Agyei F, Aikins ADG. Factors associated with treatment-seeking for malaria in urban poor communities in Accra, Ghana. Malar J. 2018;17:168.

22. Fenny AP, Asante FA, Enemark U, Hansen KS. Malaria care seeking behaviour of individuals in Ghana under the NHIS: are we back to the use of informal care? BMC Public Health. 2015;15:370.

23. Ketu south municipality. Available at https://www2.statsghana.gov. gh/docfiles/2010_District_Report/Nolta/Ketu\%20South.pdf. Accessed December 20th 2020.

24. Nkwanta south district. Available at https://www2.statsghana.gov.gh/ docfiles/2010_District_Report/Nolta/NKWANTA\%20SOUTH.pdf. Accessed December 20th 2020

25. Ho west district. Available at https://www2.statsghana.gov.gh/docfiles/ 2010_District_Report/Nolta/HO_WEST.pdf. Accessed August 13th 2021.

26. Hohoe municipality. Available at https://www2.statsghana.gov.gh/docfi les/2010_District_Report/Volta/Hohoe\%20Mun.pdf. Accessed August 13th 2021.

27. Adhikari B, Phommasone K, Pongvongsa T, Koummarasy P, Soundala $X$, Henriques $G$, et al. Treatment-seeking behaviour for febrile illnesses and its implications for malaria control and elimination in Savannakhet Province, Lao PDR (Laos): a mixed method study. BMC Health Serv Res. 2019:9:252.

28. Berendes S, Adeyemi O, Oladele EA, Oresanya OB, Okoh F, Valadez JJ. Are patent medicine vendors effective agents in malaria control? Using lot quality assurance sampling to assess quality of practice in Jigawa. Nigeria PLoS One. 2012;7: e44775.

29. Danquah DA, Buabeng KO, Asante KP, Mahama E, Bart-Plange C, OwusuDabo E, et al. Malaria case detection using rapid diagnostic test at the community level in Ghana: consumer perception and practitioners' experiences. Malar J. 2016;15:34.

30. Adibe MO, Ayogu EE, Igboeli NU. Assessment of knowledge and roles of patent medicine vendors in the implementation of national malaria treatment policy in Nigeria. World J Pharm Sci. 2016;2016(4):310-7.

31. Ladner J, Davis B, Audureau E, Saba J. Treatment-seeking patterns for malaria in pharmacies in five sub-Saharan African countries. Malar J. 2017;16:353.

32. Latunji $\mathrm{OO}$, Akinyemi $\mathrm{OO}$. Factors influencing health-seeking behaviour among civil servants in Ibadan, Nigeria. Ann Ibadan Postgrad Med. 2018;2018(16):52-60.

33. Ansah EK, Gyapong M, Narh-Bana S, Bart-Plange C, Whitty CJ. Factors influencing choice of care-seeking for acute fever comparing private chemical shops with health centres and hospitals in Ghana: a study using case-control methodology. Malar J. 2016;15:290.
34. Orem JN, Mugisha F, Okui AP, Musango L, Kirigia JM. Health care seeking patterns and determinants of out-of-pocket expenditure for malaria for the children under-five in Uganda. Malar J. 2013;12:175.

35. Dalaba MA, Welaga P, Oduro A, Danchaka LL, Matsubara C. Cost of malaria treatment and health seeking behaviour of children under-five years in the Upper West Region of Ghana. PLoS ONE. 2018;13: e0195533.

36. Agyepong IA, Abankwah DNY, Abroso A, Chun C, Dodoo JNO, Lee S, et al. The "Universal" in UHC and Ghana's National Health Insurance Scheme: policy and implementation challenges and dilemmas of a lower middle income country. BMC Health Serv Res. 2016;16:504.

37. Suswardany DL, Sibbritt DW, Supardi S, Pardosi JF, Chang S, Adams J. A cross-sectional analysis of traditional medicine use for malaria alongside free antimalarial drugs treatment amongst adults in high-risk malaria endemic provinces of Indonesia. PLoS ONE. 2017;12: e0173522.

38. Boadu AA, Asase A. Documentation of herbal medicines used for the treatment and management of human diseases by some communities in southern Ghana. Evid Based Complement Alternat Med. 2017;2017:3043061.

39. Kamat VR. "I thought it was only ordinary fever!" cultural knowledge and the micropolitics of therapy seeking for childhood febrile illness in Tanzania. Soc Sci Med. 2006;62:2945-59.

40. Ahorlu CS, Adongo P, Koenker H, Zigirumugabe S, Sika-Bright S, Koka E, et al. Understanding the gap between access and use: a qualitative study on barriers and facilitators to insecticide-treated net use in Ghana. Malar J. 2019;18:417.

41. Manu G, Boamah-Kaali EA, Febir LG, Ayipah E, Owusu-Agyei S, Asante KP. Low utilization of insecticide-treated bed net among pregnant women in the middle belt of Ghana. Malar Res Treat. 2017;2017:7481210.

42. Diema Konlan K, Japiong M, Dodam Konlan K, Afaya A, Salia SM, et al. Utilization of insecticide treated bed nets (ITNs) among caregivers of children under five years in the Ho Municipality. Interdiscip Perspect Infect Dis. 2019;2019:3693450

43. Mensah EA, Anto F. Individual and community factors associated with household insecticide-treated bednet usage in the Sunyani West District of Ghana two years after mass distribution. J Environ Public Health. 2020:2020:7054383.

44. Pulford J, Hetzel MW, Bryant M, Siba PM, Mueller I. Reported reasons for not using a mosquito net when one is available: a review of the published literature. Malar J. 2011;10:83.

45. Baume CA, Reithinger $\mathrm{R}$, Woldehanna S. Factors associated with use and non-use of mosquito nets owned in Oromia and Amhara regional states, Ethiopia. Malar J. 2009:8:264

46. Eisele TP, Thwing J, Keating J. Claims about the misuse of insecticidetreated mosquito nets: are these evidence-based? PLoS Med. 2011;8: e1001019.

47. US President Malaria Initiative. Identifying and mitigating misuse of insecticide-treated nets for fishing toolkit. 2018;(May). Available at https:// www.pmi.gov/docs/default-source/default-document-library/toolscurricula/identifying-misuse-of-itns-in-fishing.pdf?sfvrsn=9. Accessed December 20th 2020

48. Orkoh E, Annim, SK. Source and use of insecticide treated net and malaria prevalence in Ghana. Available at SSRN 3020694. 2017.

49. Olapeju B, Choiriyyah I, Lynch M, Acosta A, Blaufuss S, Filemyr E, et al. Age and gender trends in insecticide-treated net use in sub-Saharan Africa: a multi-country analysis. Malar J. 2018;17:423.

50. Garley AE, Ivanovich E, Eckert E, Negroustoueva S, Ye Y. Gender differences in the use of insecticide-treated nets after a universal free distribution campaign in Kano State, Nigeria: post-campaign survey results. Malar J. 2013;12:119.

51. Bertakis KD, Azari R, Helms LJ, Callahan EJ, Robbins JA. Gender differences in the utilization of health care services. J Fam Pract. 2000;49:147.

52. Theiss-Nyland K, Koné D, Karema C, Ejersa W, Webster J, Lines J. The relative roles of ANC and EPI in the continuous distribution of LLINs: a qualitative study in four countries. Health Policy Plan. 2017;32:467-75.

53. Mussa Soleimani A, Hassan V, Mansoreh S, Ahmad R, Farshid A, Teimur A, et al. Effects of educational intervention on long-lasting insecticidal nets use in a Malarious area, Southeast Iran. Acta Med Iran. 2012;50:279-87.

54. Ndjinga JK, Minakawa N. The importance of education to increase the use of bed nets in villages outside of Kinshasa, Democratic Republic of the Congo. Malar J. 2010;9:279. 
55. Baume CA, Franca-Koh AC. Predictors of mosquito net use in Ghana. Malar J. 2011;10:265

56. Onwujekwe O, Etiaba E, Uguru N, Uzochukwu B, Adjagba A. Towards making efficient use of household resources for appropriate prevention of malaria: investigating households' ownership, use and expenditures on ITNs and other preventive tools in Southeast Nigeria. BMC Public Health. 2014;14:315.

57. Loroño-Pino MA, Chan-Dzul YN, Zapata-Gil R, Carrillo-Solís C, Uitz-Mena A, García-Rejón JE, et al. Household use of insecticide consumer products in a dengue-endemic area in México. Trop Med Int Health. 2014;19:1267-75.

58. PMI Africa IRS (AIRS). Project Indoor Residual Spraying (IRS 2); Task Order Six. Available at https://www.pmi.gov/docs/default-source/defaultdocument-library/implementing-partner-reports/ghana-2015-sea.pdf? $s f v r s n=10$. Accessed December 20th 2020.

59. Ozims SJ, Eberendu IF. Awareness, ownership, and utilization of longlasting insecticide-treated net (LLIN) among pregnant women attending antenatal clinic in Imo State University Teaching Hospital, Orlu, Imo. Int J Res Med Health Sci. 2014;4:14-21.

60. Koenker H, Taylor C, Burgert-Brucker CR, Thwing J, Fish T, Kilian A. Quantifying seasonal variation in insecticide-treated net use among those with access. Am J Trop Med Hyg. 2019;101:371-82.

\section{Publisher's Note}

Springer Nature remains neutral with regard to jurisdictional claims in published maps and institutional affiliations.

- fast, convenient online submission

- thorough peer review by experienced researchers in your field

- rapid publication on acceptance

- support for research data, including large and complex data types

- gold Open Access which fosters wider collaboration and increased citations

- maximum visibility for your research: over $100 \mathrm{M}$ website views per year

At BMC, research is always in progress.

Learn more biomedcentral.com/submissions 